\title{
ATUAÇÃO DE EGRESSOS NO AMBIENTE SOCIOECONÔMICO ORIUNDOS DE UMA IES COMUNITÁRIA
}

\author{
PERFORMANCE IN THE SOCIOECONOMIC ENVIRONMENT OF \\ STUDENTS WHO GRADUATED FROM A COMMUNITY IHE
}

\author{
ACTUACIÓN DE EGRESADOS EN EL AMBIENTE \\ SOCIOECONÓMICO ORIUNDOS DE UNA IES COMUNITARIA
}

LUIZ CARLOS LUCKMANN ${ }^{1}$

ARISTIDES CIMADON ${ }^{2}$

${ }^{1}$ Universidade do Oeste de Santa Catarina (UNOESC), Santa Catarina/SC - Brasil

${ }^{2}$ Universidade do Oeste de Santa Catarina (UNOESC), Santa Catarina/SC - Brasil

Resumo O texto tem por objetivo analisar como se materializa a inserção de egressos de cursos de graduação no ambiente socioeconômico, oriundos de uma universidade comunitária localizada no interior do Estado de Santa Catarina. Dada a natureza do objeto, optou-se por desenvolver estudo qualitativo-exploratório, ex post facto, a partir de fontes bibliográfica, documental e de pessoas. Os dados primários foram obtidos a partir de questionário aplicado junto a 8.512 egressos de cursos de graduação, compreendendo os anos de 2015, 2016, 2017 e primeiro semestre de 2018. A realidade profissional por eles revelada apresentou-se, por vezes, contraditória ao percurso acadêmico trilhado. Constatou-se, por exemplo, que $30,68 \%$ dos egressos avaliaram o currículo de seu curso de graduação como sendo em parte ou totalmente inadequado ao exercício da profissão. Entre os indicadores considerados inadequados estão a formação para o empreendedorismo, a preparação para o exercício profissional e a articulação teoria-prática. Os resultados revelaram ainda serem poucos os egressos a estabelecerem seu próprio negócio, após a conclusão da graduação $(15,26 \%)$. Constituíram aprendizados diferenciados a realização de estágios, o trabalho de conclusão do curso, a participação em atividades complementares, em eventos e em projetos de pesquisa, extensão ou cultura.

Palavras-chave: Instituições comunitárias; Avaliação; Egressos; Empregabilidade. 
ABSTRACT This article aims at analyzing the presence in the socioeconomic environment of professionals who recently graduated, former students from a community university located in the country region of the Santa Catarina state. Given the nature of the object, we preferred to develop a qualitative-exploratory study, ex post fact, based on bibliographic sources, documents, and people. We collected the primary data from a survey conducted with 8,512 students who graduated, considering the years of 2015, 2016, 2017 and the first semester of 2018. The professional reality revealed by them was at times contradictory to the academic journey taken. We verified for instance that $30.86 \%$ of former students evaluated their undergraduate courses curriculum as being in part or totally inadequate to the professional practice. Among the mentioned indicators considered inadequate, we can list the education towards entrepreneurship, the preparation to the professional practice and the theoretical-practice articulation. The results also revealed that just a small number of graduated students started their business after finishing their courses (15.26\%). Among the learning items considered to be distinguished, we can mention the internship conduction, the graduation course work, the participation in complementary activities, in events and research, extension or cultural projects.

Key wORds: COMmUnity institutions; Evaluation; Graduates; Employability.

Resumen El texto pretende analizar como si materializa la inserción de los egresados de cursos de grado en el ambiente socioeconómico, oriundos de una institución comunitaria de educación superior localizada en el interior del estado de Santa Catarina. Dada la naturaleza del objeto, elegimos desarrollar estudio cualitativo exploratorio, ex post facto, a partir de fuentes bibliográfica, documental y de personas. Los datos primarios se obtuvieron de cuestionario aplicado con 8.512 egresados de cursos de grado, incluyendo los años de 2015, 2016, 2017 y primer semestre de 2018. La realidad profesional por ellos revelada se presentó, a veces, contradictoria a lo largo de la trayectoria académica. Se observó, por ejemplo, que $30.68 \%$ de los graduados evaluaron el currículo de su curso de grado como total o parcialmente inapropiado para el ejercicio de la profesión. Entre los indicadores considerados inapropiados son la formación para el emprendimiento, la preparación para la práctica profesional y la articulación teoría-práctica. Los resultados han revelado, además, que son pocos los egresados que constituyeron su propio negocio después de la graduación (15.26\%). Constituyeron aprendizajes diferenciados la realización de pasantías, los trabajos de conclusión de curso, la participación en actividades complementarias, en eventos y proyectos de investigación, extensión y cultura.

Palabras Clave: Instituciones comunitarias; Evaluación; Egresados; Empleabilidad.

\section{INTRODUÇÃo}

O compromisso de uma instituição universitária com seus estudantes não termina com a entrega do diploma; estende-se por toda a vida, especialmente quando, uma vez formados, adentram ao mundo do trabalho. A política de acompanhamento de egressos está prevista no Sistema Nacional de Avaliação da Educação Superior (Sinaes), instituído 
pela Lei $\mathrm{n}^{\circ}$. 10.861, de 14 de abril de 2004 (BRASIL, 2004). O texto incluiu, entre outros elementos, a avaliação da atuação dos egressos no ambiente socioeconômico e sua participação na vida da instituição na qual se formaram.

Contudo, poucas são as instituições de ensino superior que levam a cabo tal política, abrindo-se mão de um dos mais importantes mecanismos de autoavaliação institucional. Outras a adotam apenas para cumprir formalidades, restringindo-se à aplicação de questionários, cujos resultados não se traduzem em ações e programas de melhoria dos projetos pedagógicos dos cursos, em prejuízo à qualidade educacional.

Vive-se hoje num contexto de acelerada evolução tecnológica e de mudanças paradigmáticas de toda natureza, impactando nas organizações e dificultando a inserção dos egressos de cursos de graduação no mundo do trabalho. Saímos de um mundo de previsibilidades, em que as pessoas se formavam na certeza de exercer a profissão que escolheram e estamos passando para um mundo de incertezas, onde as pessoas se formam, mas não sabem se vão exercer a profissão que abraçaram (SANTOS, 1988).

Nessa mesma direção, o documento resultante da Conferência Mundial sobre Educação Superior para o Século XXI, ao tratar das missões e funções da educação superior, adverte que, nos dias de hoje, não é mais possível exigir que as instituições universitárias formem as pessoas para uma única atividade humana. No artigo $1^{\circ}$. da Declaração, lê-se:

\begin{abstract}
Afirmamos que as missões e valores fundamentais da educação superior, em particular a missão de contribuir para o desenvolvimento sustentável e o melhoramento da sociedade como um todo, devem ser preservados, reforçados e expandidos ainda mais, a fim de:

a) educar e formar pessoas altamente qualificadas, cidadãs e cidadãos responsáveis, capazes de atender às necessidades de todos os aspectos da atividade humana, oferecendo-lhes qualificações relevantes, incluindo capacitações profissionais nas quais sejam combinados conhecimentos teóricos e práticos de alto nível mediante cursos e programas que se adaptem constantemente às necessidades presentes e futuras da sociedade (UNESCO, 1998).
\end{abstract}

O desafio, portanto, não parece apenas o de "formar", mas despertar a consciência para uma formação permanente e plural, cujas capacidades de resolver problemas e de inovar sejam habilidades essenciais a serem desenvolvidas. Como saber se essa função vem sendo cumprida pela universidade? Quem melhor poderia responder a essa questão são os egressos do ensino superior, uma vez que são eles que, uma vez formados, passam por experiências as mais diversas e por elas são impactados ao ingressarem no mundo do trabalho.

Dada a natureza do presente estudo, optou-se por desenvolver pesquisa exploratória, de caráter quantitativo/qualitativo. Na abordagem qualitativa fez-se uso de análise textual, alargando-se a visão meramente estatística dos dados. Para dar maior concretude à análise, procedeu-se a um estudo do tipo ex post facto, tomando-se como "caso" uma universidade localizada no interior de Santa Catarina, doravante denominada de IES, pertencente ao modelo comunitário de educação superior.

O processo de análise tomou como referência fontes de natureza bibliográfica, documental e de pessoas. Os dados primários foram obtidos a partir da aplicação de questionário elaborado pela Comissão Própria de Avaliação (CPA) daquela instituição e aplicado junto a 
8.512 egressos de cursos de graduação dos sete últimos semestres, compreendendo os anos de 2015 a 2017 e o primeiro semestre de 2018. Responderam ao questionário 1.206 egressos, uma taxa de retorno de $14,17 \%$. O instrumento foi disponibilizado pela ferramenta google forms, no mês de agosto de 2018.

O questionário foi elaborado a partir de categorias definidas a priori. Para fins do presente estudo, optou-se por analisar somente aquelas categorias mais próximas ao tema proposto, quais sejam: atuação dos egressos no ambiente socioeconômico; faixa salarial e ascensão social; diferenciais observados pelos egressos no processo de formação; e adequação dos cursos às necessidades profissionais. Buscou-se alternar dados e informações coletados com comentários e depoimentos atribuídos aos egressos, procurando-se atribuir significado e qualidade à análise.

Antes de adentrar à análise dos resultados, fez-se necessário abordar, brevemente, duas seções: uma tratando da política de acompanhamento de egressos prevista na Lei do Sinaes (Lei ${ }^{\circ} .10 .861$, de 14 de abril de 2004) e no próprio Plano de Desenvolvimento Institucional (PDI) da IES; e outra caracterizando o modelo comunitário de educação superior, ao qual pertence a IES em estudo.

\section{SOBRE A POLIÍTICA DE ACOMPANHAMENTO DE EGRESSOS}

As IES brasileiras pouco têm se apropriado de informações advindas de egressos de cursos de graduação, abrindo mão de importante mecanismo de avaliação da qualidade educacional que oferecem. Pesquisa realizada pelo Instituto Nacional de Estudos e Pesquisas Educacionais Anísio Teixeira (Inep) constatou que 74,8\% das instituições de ensino superior brasileiras não apresentavam, em seus relatórios de autoavaliação, informações advindas de instrumentos de avaliação pelos egressos, particularmente em relação a sua inserção, enquanto profissionais, no contexto socioeconômico (INEP, 2015, p. 46). O mesmo estudo constatou que número significativo de IES sequer possui proposta ou intenção de implantar política visando o acompanhamento dos egressos; outras se encontram em processo inicial de estabelecimento dessa política, ou simplesmente a ignoram, em desacordo com a Lei do Sinaes, que considera, como pressuposto para a qualidade educacional, não somente a inserção dos egressos no mundo do trabalho, mas também a sua participação na vida da instituição na qual se formaram.

Examinando a literatura sobre essa questão, observa-se que raros são os estudos que analisam, por exemplo, a atuação dos egressos no ambiente socioeconômico, ou a compatibilidade dos projetos pedagógicos de curso com as demandas do mundo do trabalho. Andriola (2014), ao realizar pesquisa com egressos dos cursos de graduação da Universidade Federal de Goiás (UFG), formados entre 2009 e 2011, localizou onze pesquisas similares à sua, a primeira delas realizada pela Universidade de Brasília (UnB) junto a egressos dos cursos de Arquitetura e Urbanismo e Desenho Industrial, formados entre 1993 e 2002. O autor identificou, ainda, estudos feitos pela Universidade Federal da Paraíba (UFPb), com egressos de cursos de graduação do ano de 1994, pela Universidade de São Paulo (USP), com egressos do curso de Nutrição, formados no período entre 1990 e 1996 e pela Universidade Federal do Ceará (UFC), com egressos de cursos de graduação formados no período 2003-2004. 
Andriola menciona ainda os estudos de Colenci e Berti (2012), Carrijo, Bezerra, Munari e Medeiros (2007), Meira e Kurcgant (2009), Santos e Sanna (2003) e Bardagi et al. (2008), todos realizados junto a egressos de cursos de graduação de universidades públicas e privadas. Mais recentemente, Lima e Andriola (2018), em continuidade ao trabalho anterior, localizaram outros dez artigos, uma dissertação e duas teses de doutorado versando sobre o tema, publicados entre os anos de 2014 e 2016. Muitos desses estudos versaram acerca das condições de empregabilidade dos egressos e a respeito da coerência entre currículo acadêmico e demandas do mercado de trabalho.

No ano de 2017, Simon e Pacheco (2017) publicaram trabalho levantando as políticas de acompanhamento de egressos adotadas no sistema público de educação superior brasileiro. Os resultados desse estudo revelaram serem poucas as IES públicas que avançaram em suas políticas de acompanhamento de egressos.

No ano de 2018, destacamos, entre outras publicações, os artigos de Shiwa e João (2018) e de Emmi, Silva e Barroso (2018). O texto de Shiwa e João apresenta estudo sobre os egressos do curso de Fisioterapia da Faculdade de Medicina da Universidade de São Paulo (FMUSP). Já o artigo de Emmi, Silva e Barroso faz uma análise da importância do estágio extracurricular na formação profissional em Odontologia na percepção de egressos da Faculdade de Odontologia da Universidade Federal do Pará (UFPA).

Grande parte desses estudos teve por objetivo apreender as percepções dos egressos em relação ao processo de formação recebido e sua inserção no mundo laboral, uma vez que, somente eles, são capazes de avaliar que contribuições o curso no qual se formaram trouxe para a sua atuação no mundo do trabalho (ANDRIOLA, 2018, p. 209).

$\mathrm{Na}$ IES locus do presente estudo, a institucionalização de política de acompanhamento de egressos está prevista no texto de seu Plano de Desenvolvimento Institucional (PDI). Nele lê-se: “O compromisso com os discentes de uma instituição universitária não se encerra com a entrega do diploma. Com base nessa prerrogativa, a Unoesc, enquanto instituição socialmente responsável, adota como política a construção de vínculos permanentes com os seus egressos" (UNOESC, PDI, 2018, p. 126).

Os vínculos com os egressos são detalhados no Programa de Acompanhamento de Egressos, previsto no mesmo PDI (UNOESC, 2018, p. 126). O Programa conta com uma coordenadoria de gestão das relações com diplomados, integrada por equipe de profissionais responsáveis pela execução das ações.

Para manter o vínculo e a comunicação com os egressos, a IES desenvolveu duas ferramentas on-line, disponibilizadas em seu site: o Portal do Diplomado, onde o egresso pode cadastrar-se e se manter informado a respeito de cursos, eventos, palestras e outras atividades ofertadas pela IES; e o Unoesc Carreiras, cujo objetivo é o de viabilizar atividades de estágio, monitoria e trabalho a estudantes em processo de formação, assim como propiciar a colocação de egressos no mercado de trabalho (UNOESC, PDI, 2018, p. 126).

As IES brasileiras, de um modo geral, também começam a adotar portais virtuais como estratégia de acompanhamento de egressos, contudo, no entender de Simon e Pacheco $(2017$, p. 96), “[...] a maioria deles apresenta limitações, tais como conteúdos desatualizados, pouca interatividade e uma carência de informações que indique vantagens e benefícios que os egressos podem obter ao se cadastrar e permanecerem ativos no portal [...]". 
Ainda segundo o PDI da IES:

O acompanhamento de egressos ocorre, igualmente, mediante apresentação e realização de projetos de pesquisa por docentes pesquisadores, com a finalidade de analisar a atuação profissional, a empregabilidade e integração dos egressos no mundo do trabalho, bem como o ambiente social em que estão inseridos e a relação com as entidades de classes e empresas. Os resultados dessas pesquisas têm servido de reflexão e subsídio às mudanças constantes processadas nos Projetos Pedagógicos de Curso (UNOESC, PDI, 2018, p. 126-127).

Como amostra dessa política, indicamos a publicação de artigo por Sopelsa, Rios e Lückmann (2012), analisando o perfil de formação apropriado à empregabilidade de egressos dos cursos de Administração, Ciências Contábeis, Fisioterapia, Engenharia Civil e Publicidade e Propaganda daquela IES.

Localizamos, igualmente, na mesma IES, recente publicação com análise dos resultados da avaliação da atuação dos diplomados no ambiente socioeconômico, organizado e publicado pela Comissão Própria de Avaliação (UNOESC, CPA, 2018). Estudo semelhante também havia sido feito em 2014, cujos dados foram analisados no Relatório de Autoavaliação Institucional da IES, do ano de 2014.

O modelo brasileiro de avaliação para o credenciamento e renovação de credenciamento de IES, bem como, para reconhecimento e renovação de reconhecimento de cursos, não tem dado ênfase à questão da inserção dos egressos no mundo do trabalho. A Organização para a Cooperação e Desenvolvimento Econômico (OCDE), em um de seus últimos relatórios, faz uma crítica à eficácia do Exame Nacional de Desempenho do Estudante (Enade), considerando-o inapropriado para avaliar os grandes objetivos pelos quais os estudantes ingressam no ensino superior: a formação e sua inserção no mercado de trabalho (PALHARES, 2018). Na mesma direção, Bordignon e Cimadon (2012) chamam a atenção para as fragilidades do Enade, uma vez que ele afronta o princípio da autonomia universitária e não avalia os propósitos da qualidade da formação dos universitários.

\section{O modelo comunitário de educação superior}

A literatura que trata do modelo comunitário de educação superior (MACHADO, 2009; FRANTZ; SILVA, 2002; SCHMIDT, 2009; LÜCKMANN; CIMADON, 2015) o tem caracterizado como sendo um sistema público não estatal de educação superior, instituído pela iniciativa de entidades comunitárias e do poder público municipal, impulsionados pelo desejo de oportunizar o acesso ao ensino superior a regiões interioranas distantes dos grandes centros urbanos do país. Suas IES predominam nos Estados de Santa Catarina (SC) e Rio Grande do Sul (RS). Em SC, integram-se à Associação Catarinense das Fundações Educacionais (Acafe); no RS, ao Consórcio das Universitárias Comunitárias Gaúchas (Comung). Juntas, as duas associações integram 27 IES comunitárias, a maioria delas com status de universidade.

As IES comunitárias possuem características próprias, muitas delas não encontradas em outros modelos de educação superior existentes no país (FRANTZ; SILVA, 2002). 
Foram criadas por iniciativa da sociedade civil e do poder público e constituídas sob a forma de fundação ou associação de direito privado; atendem aos mesmos princípios constitucionais reservados às IES públicas estatais; não almejam lucro; seus bens não são de propriedade de particulares; contemplam membros da sociedade civil em seus órgãos deliberativos; prestam contas à sociedade e ao poder público; são responsáveis socialmente perante as comunidades de seu entorno; participam do processo de desenvolvimento local e regional (SCHMIDT, 2009; BRASIL, 2013).

São, portanto, instituições que exercem papel social preponderante no processo de interiorização e de democratização da educação superior. O modelo foi reconhecido pelo sistema nacional de educação quando, por ocasião da promulgação da Lei $n^{\circ} .12 .881$, de 12 de novembro de 2013, cujo teor "dispõe sobre a definição, qualificação, prerrogativas e finalidades das Instituições Comunitárias de Educação Superior - ICES, disciplina o Termo de Parceria e dá outras providências" (BRASIL, 2013).

A IES tomada como "caso" no presente estudo é parte constituinte desse modelo. Ao final da década de 1960, foi protagonista no processo de interiorização do ensino superior em SC, até então exclusivo à faixa litorânea. Estabeleceu-se na mesorregião Oeste do Estado como Fundação criada (em 1968) pelo poder público municipal, com o apoio de entidades da sociedade civil. Mais tarde, nos anos 1990, já com o status de universidade, participou da expansão do ensino superior na região, tornando-se uma das mais influentes universidades da mesorregião Oeste catarinense (LÜCKMANN, 2018).

A IES diplomou, entre 1974 e 2017, 46.731 profissionais nas mais diversas áreas do conhecimento (UNOESC, 2018, p. 63). Em 2018, o Ranking Universitário Folha (RUF) a avaliou como sendo uma das melhores universidades da região, considerando-se os quesitos pesquisa, internacionalização, inovação, ensino e mercado. No indicador mercado, que avalia a empregabilidade dos diplomados, a IES ocupou a $71^{\text {a }}$ posição geral, a $3^{\mathrm{a}}$ posição no Estado de Santa Catarina e a $1^{\mathrm{a}}$ no Oeste de Santa Catarina (FOLHA DE SÃO PAULO, 2018). É nesse contexto que passamos a analisar os dados e informações obtidos em pesquisa realizada junto aos egressos dos cursos de graduação.

\section{A atuação dos egressos no ambiente socioeconômico}

O corpus da análise tem por fonte os resultados da pesquisa sobre a atuação dos diplomados no ambiente socioeconômico encabeçada pela CPA da IES tomada como "caso" e publicado em outubro de 2018 (UNOESC, 2018). Para ouvir os egressos a respeito do tema, foram dirigidas quatro questões: "Você está exercendo atividade profissional atualmente? Caso você esteja exercendo atividade profissional, em qual ramo da economia você trabalha? Caso você constituiu seu próprio negócio, como a ideia surgiu? Você teve dificuldades de ingressar no mercado de trabalho assim que se formou? Quais foram as principais dificuldades para ingressar no mercado de trabalho?" (UNOESC, 2018).

As respostas a essas questões necessitam ser analisadas à luz das mudanças que ocorrem no mundo do trabalho, por conta da desaceleração da economia e do ritmo de geração de empregos, fenômenos constatados no país a partir de 2014, produzindo impactos adversos à empregabilidade, sobretudo dos jovens. 
A proporção de egressos que afirmaram estar exercendo atividade profissional atingiu o patamar de $87,72 \%$, dos quais $67,16 \%$ atuam na respectiva área de formação e $20,56 \%$ em áreas distintas à formação recebida. O percentual de egressos que ainda não se encontrava inserido no mercado de trabalho foi de $12,27 \%$, acima da taxa oficial do País, levantada pela Pesquisa Nacional por Amostra de Domicílios Contínua Trimestral (PNAD CONTÍNUA TRI), no terceiro trimestre de 2018, que foi de $11,9 \%$. A taxa de desemprego dos egressos da Unoesc é, portanto, superior à taxa verificada no País e maior ainda no Estado de Santa Catarina (6,2\%). O Gráfico 1 apresenta a posição dos egressos no mercado de trabalho.

\section{Gráfico 1 - Egressos exercendo atividade profissional}

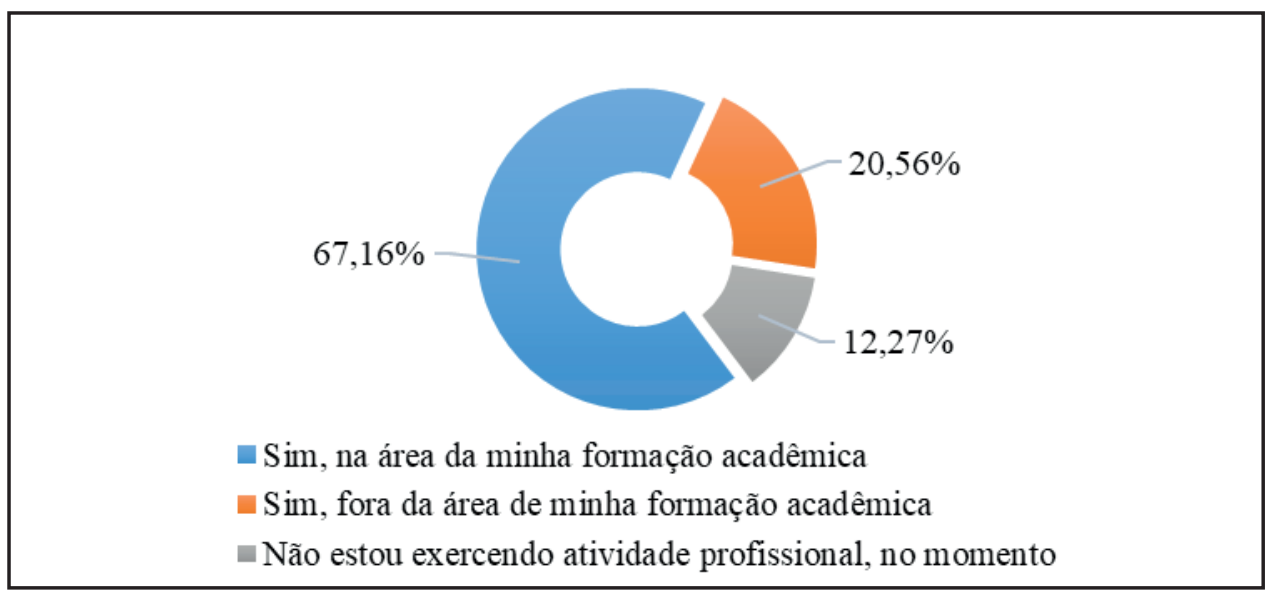

Fonte: Comissão Própria de Avaliação (UNOESC, 2018), p. 16.

As maiores taxas de desemprego estão na área das engenharias, como Engenharia Sanitária e Ambiental (66,67\%), Engenharia Mecânica (33,33\%), Engenharia Elétrica, também (33,33\%), Engenharia de Produção Mecânica (25\%) e Engenharia Civil $(22,45 \%)$. Egressos dos cursos de Agronomia, com 24,14\% de desocupados e de Medicina Veterinária, com $21,74 \%$, também enfrentam altos índices de desemprego.

A IES em estudo não prevê política para diminuir os impactos do desemprego em seu PDI, por exemplo, considerar, em sua expansão de vagas, aqueles cursos com maior escassez de postos de trabalho, como sugerem Sampaio, Lopes, Thomaz e Apolinário (2013) em estudo sobre os egressos e sua inserção no mundo do trabalho.

A economia brasileira se encontra formalmente em recessão desde 2014 (BARBOSA FILHO, 2017), refletindo no aumento do desemprego, da informalidade e da queda da renda do trabalhador. Comumente, os primeiros profissionais a serem afetados pelas crises econômicas são, de fato, os engenheiros, uma vez que os setores mais atingidos por elas são os da construção civil e da indústria. Segundo dados do Cadastro Geral de Empregados e Desempregados (Caged) do Ministério do Trabalho, desde 2014, o número de profissionais de engenharia demitidos é maior que o de contratados (ESTADÃO, 2017). 
Por sua vez, egressos de cursos como Medicina $(0,0 \%)$, Sistemas de Informação $(0,0 \%)$, Engenharia de Alimentos $(0,0 \%)$, Educação Física (4,76\%), Ciências Contábeis (4,96\%), Arquitetura e Urbanismo (6,67\%), Fisioterapia (6,67\%), Administração (7,52\%) não estão sofrendo os impactos do desemprego na mesma proporção que as engenharias.

Os resultados também indicaram que a maioria dos egressos dos cursos de graduação da IES encontra-se exercendo a profissão na área em que receberam formação universitária (67,16\%). Parece um dado razoável, contudo, na maior parte das universidades federais, o percentual é maior, como na Universidade Federal do Ceará $(81,8 \%)$ (ANDRIOLA, 2018, p. 212).

Em vários cursos da IES, o percentual de egressos atuando fora da área de formação é elevado, como ocorre nos cursos de Engenharia Elétrica (50\%), Design (36,36\%), Ciências Biológicas - Bacharelado (35,29\%), Zootecnia (33,33\%), Direito, (30,73\%), Ciências Contábeis (27,66\%), Administração (24,81\%), Arquitetura e Urbanismo (24,44\%), Psicologia (23,88\%), Engenharia Mecânica (22,22\%) e Engenharia Civil (20,41\%).

Dizia um egresso do curso de Psicologia da IES: "De certa forma é frustrante se formar numa profissão que se gosta e não conseguir atuar na mesma". Muitos desistem de atuar na área de formação antes mesmo de concluir o curso, uma vez que, como estudantes, já se encontram inseridos no mundo do trabalho, porém, em outras áreas.

Os dados disponibilizados pela IES em relação a esse indicador são precários e revelam a necessidade de se recorrer a um estudo de maior profundidade, buscando-se identificar, por exemplo, os fenômenos que estão por trás dessa distorção.

Outro indicador considerado no instrumento aplicado aos egressos dos cursos de graduação da IES revelou que 52,57\% dos que responderam ao questionário já se encontravam inseridos no mercado de trabalho, antes mesmo de se formar. Os demais informaram ter ingressado no mercado de trabalho assim que se formaram (20,48\%), ou ter levado de um a dois anos para nele ingressar (11,77\%).

Quando o emprego coincide com a mesma área de formação, certamente os ganhos em termos de experiência são maiores que aqueles que trabalham em área diversa. Bem expressou um egresso do curso de Ciências da Computação: "Como eu já estava atuando na área antes mesmo de iniciar a faculdade, o curso me fez aprimorar os conhecimentos, evoluindo muito como profissional".

Essa realidade estende-se a todas as IES, contudo, é particularmente peculiar às universidades do segmento comunitário de educação superior, cujos estudantes, em sua maioria, acabam tendo que conciliar estudo e trabalho, dadas suas características socioculturais, como o baixo capital econômico e cultural de suas famílias (SCHMIDT, 2018).

As principais dificuldades encontradas pelos egressos da IES, ao adentrarem no mundo do trabalho, têm sido a falta de experiência profissional (29,52\%), a fraca demanda de trabalho na área de formação $(20,41 \%)$ e as dificuldades para serem aprovados em processos seletivos ou em concursos públicos $(8,10 \%)$. Percentual de $23,44 \%$ respondeu não ter tido dificuldades para ingressar no mercado de trabalho.

Em seus depoimentos, vários egressos fizeram menção à falta de experiência profissional para ingressar no mercado de trabalho, como foi o caso de um egresso do curso de Engenharia de Alimentos: 
Acredito que a IES deveria incentivar visitações às indústrias para que o acadêmico possa estar mais familiarizado com o mercado de trabalho quando se formar. Acredito também que mais de um estágio seria ideal para o aprendizado, pois nada como estar inserido em determinado processo para aprender sobre o mesmo.

Outro egresso do curso de Psicologia assim se expressou: "Infelizmente, os acadêmicos se formam, mas não são preparados para entrar no mercado de trabalho; e percebo que, como eu, muitos colegas que se formaram comigo estão na mesma situação".

A falta de experiência profissional poderia estar sendo minimizada pela instituição em estudo mediante implementação de política visando a ampliação de oportunidades de estágios durante o processo de formação de seus estudantes. Os próprios estudantes que responderam ao questionário assinalaram que, entre as atividades que constituíram aprendizados diferenciados e significativos em seu processo de formação, está, em primeiro lugar, o estágio profissional (37,86\%), seguido pela experiência vivenciada quando por ocasião da produção do trabalho de conclusão de curso $(19,54 \%)$ e pela participação em eventos (16,24\%).

O estágio profissional também foi apontado como imprescindível à formação profissional em alguns comentários, entre os quais, o de um egresso do curso de Ciências Biológicas: "Eu, como graduada, senti a falta de um estágio. Considero ser este o motivo pelo qual muitos colegas de turma não estarem trabalhando na área. Não tivemos estímulos para buscar estágio".

A universidade brasileira, pelo fato de ter nascido sob a influência do modelo napoleônico de universidade (SILVEIRA; BIANCHETTI, 2016), vem priorizando o ensino voltado à preparação de profissionais para o mercado de trabalho. Contudo, para além da formação profissional, o empreendedorismo e as competências a ele inerentes constituem um dos vetores mais importantes da missão universitária neste início de século, assim como a pesquisa. Hoje, a aquisição de conhecimentos técnicos voltados apenas para a inserção no mercado de trabalho não mais é suficiente; é necessário promover, concomitantemente, a formação para o empreendedorismo como instrumento fundamental de inclusão social (COSTA; CARVALHO, 2011, p. 107).

O estudo realizado com os egressos da IES abordou essa questão, uma vez que a formação para o empreendedorismo está entre as competências que fazem parte do perfil profissional a ser formado, previsto no PDI (UNOESC, 2018, p. 37). E se verificou que apenas $15,26 \%$ deles constituíram seu próprio negócio ao saírem da universidade.

O problema fica mais evidenciado ao se constatar que, para 50,54\% dos egressos que se tornaram empreendedores, o negócio foi pensado e desenvolvido a partir de suas próprias ideias, não necessariamente relacionadas à sua formação graduada. Outros $29,35 \%$ afirmaram ter constituído o próprio empreendimento por influência de amigos e familiares. Apenas 20,11\% afirmaram tê-lo constituído a partir do trabalho de conclusão de curso de graduação $(11,96 \%)$, ou de pós-graduação lato sensu $(3,26 \%)$, ou pelo fato de ter participado de projeto de pesquisa na área de inovação $(4,89 \%)$, como mostra o gráfico. 


\title{
Gráfico 2 - Surgimento da ideia da constituição de negócio próprio
}

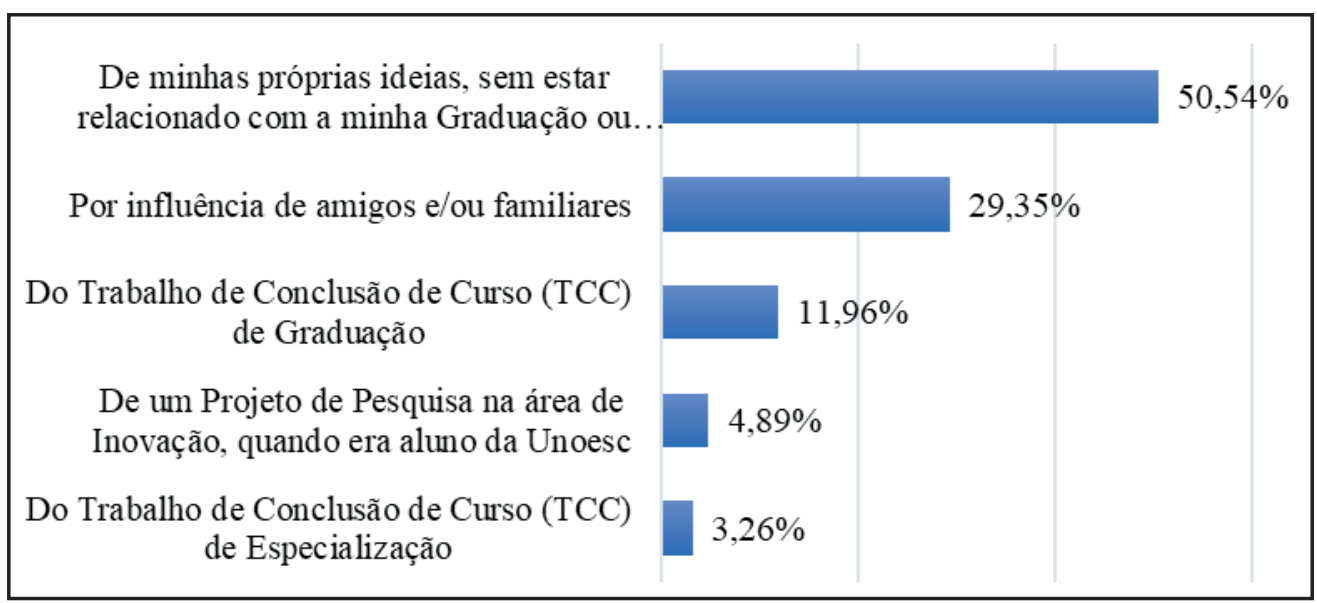

Fonte: Comissão Própria de Avaliação (UNOESC, 2018), p. 20.

Chamou a atenção a fala de um egresso do curso de Direito a esse respeito:

\begin{abstract}
A instituição é ótima em passar conhecimentos, porém, o mercado de trabalho exige mais que isso. Aulas sobre experiências práticas, palestras sobre advocacia na prática, gestão de escritório e empreendedorismo seriam fundamentais para ampliar os horizontes dos acadêmicos e formar profissionais mais preparados.
\end{abstract}

Na mesma direção, um egresso do curso de Engenharia Civil observou: "Acredito que a principal dificuldade que enfrentei no mercado de trabalho foi empreender; durante a graduação tivemos uma leve pincelada".

Os cursos da IES com maior percentual de egressos empreendendo negócios próprios foram os de Arquitetura e Urbanismo (40\% dos egressos), Educação Física - Bacharelado (40\%), Engenharia Civil (30,61\%), Sistemas de Informação (29,41\%), Publicidade e Propaganda (25\%) e Agronomia (20,69\%) (UNOESC, 2018, p. 20).

Diante da alta taxa de desemprego, das grandes mudanças tecnológicas, da permanente inovação, dos novos movimentos da economia global, que atingem particularmente os jovens à procura da primeira oportunidade de trabalho, é preciso que as IES brasileiras e, particularmente a IES em estudo, não abram mão de sua obrigação de formar profissionais competentes para o mercado de trabalho, contudo, também não podem deixar de estimular a formação para o empreendedorismo.

\section{Faixa salarial e ascensão social}

A maioria (80,93\%) dos egressos dos cursos de graduação da IES em estudo informou receber proventos mensais de até quatro salários mínimos $(\mathrm{R} \$ 3.816,00)$. São, portanto, trabalhadores de classes sociais D $(39,64 \%)$ e E $(41,29 \%)$. Outros 15,92\% informaram receber entre quatro e dez salários mínimos, integrando a classe social C. Percentual pe- 
queno $(3,15 \%)$ encontra-se na faixa acima de 10 salários, pertencendo às classes sociais $\mathrm{B}$ e A, como ilustra a Tabela 1. Para posicioná-los nas classes sociais, considerou-se o salário mínimo do ano de 2018 (R \$954,00) e o salário individual e atual por eles informado, ignorando-se eventuais patrimônios e a renda dos demais membros da família.

Tabela 1 - Faixa salarial individual dos egressos e respectivas classes sociais

\begin{tabular}{cccc}
\hline Classe & Número de SM & Renda & \% de Diplomados \\
\hline A & Acima de 20 SM & $19.080,00$ ou mais & $0,83 \%$ \\
B & De 10 a 20 SM & Entre 9.540,00 e 19.080,00 & $2,32 \%$ \\
C & De 4 a 10 SM & Entre 3.816,00 e 9.540,00 & $15,92 \%$ \\
D & De 2 a 4 SM & Entre 1.908 e 3.816,00 & $39,64 \%$ \\
E & Até 2 SM & Até $1.908,00$ & $41,29 \%$ \\
\hline
\end{tabular}

Fonte: Comissão Própria de Avaliação (UNOESC, 2018), p. 22.

A ascensão social em termos salariais conquistada pelos egressos em função da diplomação constituiu outro indicador investigado pela CPA da IES. O estudo revelou que, para $48,02 \%$ dos egressos que já se encontravam inseridos no mercado de trabalho antes da formatura, o curso de graduação realizado não possibilitou qualquer aumento salarial em relação ao salário anterior. Para 30,73\% deles, o aumento ficou entre $10 \%$ e 30\%; já para $21,26 \%$, a graduação possibilitou aumento superior a 30\%, como mostra o Gráfico 3 .

Os dados contrastam com levantamento feito pela Organização para a Cooperação e Desenvolvimento Econômico (OCDE), cujos resultados indicaram que, com um diploma de nível superior na mão, um trabalhador brasileiro ganha, em média, 140\% a mais do que um profissional que parou os estudos no ensino médio (UOL EDUCAÇÃO, 2018).

\section{Gráfico 3 - Aumento salarial proporcionado pela graduação}

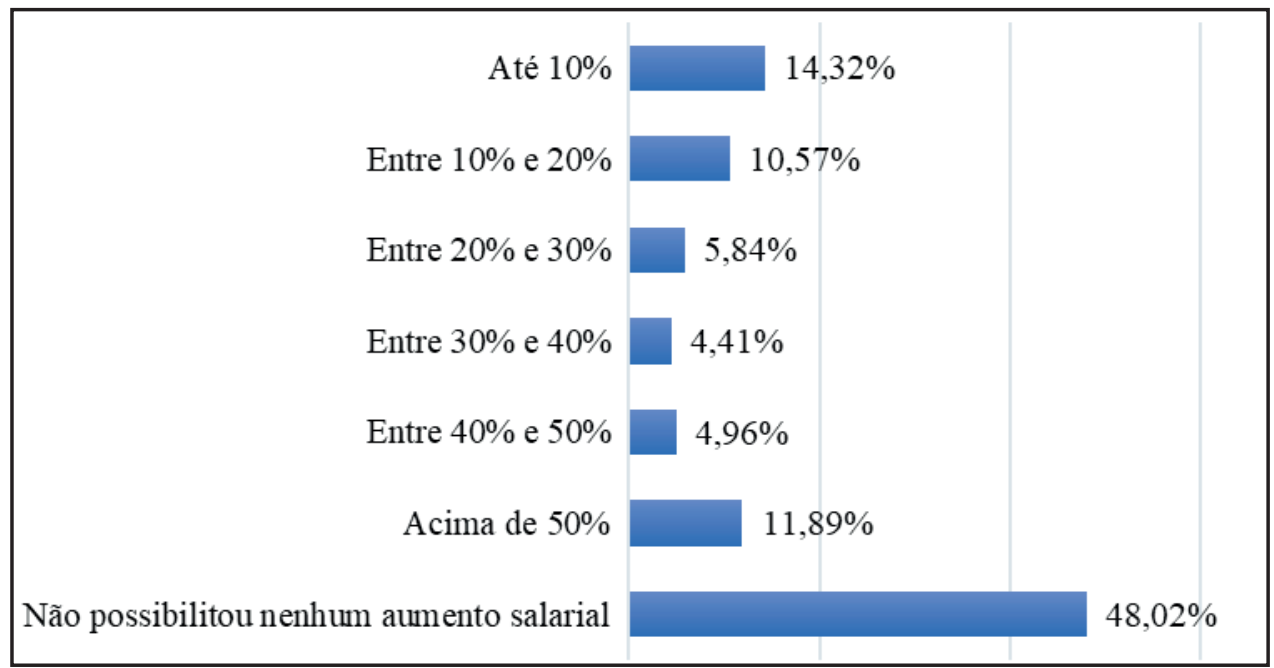

Fonte: Comissão Própria de Avaliação (UNOESC, 2018), p. 24. 
A baixa ascensão social constatada entre os egressos dos cursos de graduação da IES remete aos estudos de Bourdieu (1988) acerca da mobilidade social francesa dos anos 1970, cujos resultados contrapuseram a ideia de que exista, necessariamente, uma relação causal entre formação superior e empregabilidade, comumente defendida, como se o diploma fosse fator único e decisivo para a obtenção de emprego e melhoria salarial dos indivíduos. Para Bourdieu, a ascensão social está relacionada com a classe social a qual o indivíduo pertence; e constatou em suas pesquisas que filhos de classes sociais econômica e culturalmente mais favorecidas possuem mais oportunidades de ascensão social que filhos de classes populares (LEMOS; DUBEUX; SOARES PINTO, 2009).

Os egressos da IES, como já vimos, são, em sua maioria, oriundos de classes sociais D e E $(80,93 \%)$ e recebem renda individual de até quatro salários mínimos. Suas oportunidades de inserção no mercado de trabalho e de ascensão social certamente são menores que as de egressos de classes sociais A e B.

$\mathrm{Na}$ percepção dos egressos, no entanto, a própria instituição formadora é parte do problema. Em um dos depoimentos, lemos:

\footnotetext{
Na faculdade ninguém me disse que era essencial/necessário fazer um estágio, ninguém me mostrou o caminho das pedras. Se eu tivesse um aconselhamento correto, hoje estaria ganhando o dobro do salário. Pude notar que a maioria dos meus colegas estão perdidos; se tivesse alguém para nos ensinar e mostrar todas as opções e caminhos que poderíamos seguir quando formados [...] teríamos tempo hábil para procurar um estágio ou cursos complementares para entrar no mercado de trabalho mais qualificados e preparados [...].
}

Os dados relativos à renda dos egressos da IES em estudo indicam para a necessidade de se ampliar os programas de inclusão social, entre eles, os que concedem bolsas de estudos a estudantes carentes, pertencentes às classes sociais $\mathrm{D}$ e $\mathrm{E}$.

\section{Adequação da formação às necessidades profissionais}

O modelo de formação comumente adotado pelas universidades brasileiras está centrado na aquisição de conhecimentos, sem muita preocupação com a aprendizagem de competências profissionais, distanciando-se das necessidades do mundo do trabalho. Os projetos pedagógicos de curso raramente preveem alternância entre teoria e prática, ou mesmo entre formação teórica e situações reais do mundo do trabalho. Sem uma intrínseca relação entre teoria e prática, mais concretamente, entre conhecimento teórico e trabalho profissional, não há formação integral do indivíduo (TINTI, 2015).

No PDI da IES em estudo, lê-se: "O egresso formado pela Unoesc deverá estar preparado para ingressar no mundo do trabalho e do empreendedorismo" (UNOESC, 2018, p. 36). Na mesma direção, o perfil profissional definido no PDI sugere que o egresso esteja "preparado para atuar profissionalmente, utilizando os fundamentos teórico-metodológicos da área de formação, com base nos contextos científicos, sociais, econômicos, políticos, tecnológicos e culturais" (UNOESC, 2018, p. 36). Estaria a Instituição cumprindo com esse desafio? 
O instrumento de pesquisa aplicado aos egressos da IES contemplou essa questão dirigindo algumas perguntas que pudessem contrapor o processo de formação por eles recebido na graduação com as reais necessidades vivenciadas no cotidiano profissional. Para cada questão, os egressos atribuíram um conceito, numa escala de 1 a 5 , onde o conceito 1 seria igual a insuficiente; o conceito 2, igual a razoável; o conceito 3 , igual a bom; o conceito 4, igual a muito bom; e o conceito 5 , igual a excelente.

Os conceitos atribuídos aos indicadores "preparação ao exercício profissional e ao empreendedorismo, oportunidade de estágio profissional e articulação entre teoria e prática" evidenciaram estar havendo uma lacuna entre formação acadêmica e as reais necessidades de qualificação exigidas pelo mundo do trabalho.

Essa constatação foi reforçada em alguns depoimentos proferidos pelos egressos. Um egresso do curso de Engenharia Civil observou: "Durante meu curso de graduação [...] senti muita falta da articulação da teoria com a prática". Outro egresso do curso de Enfermagem fez menção à importância da pesquisa e do estágio profissional no processo de formação:

Eu desejaria que a instituição proporcionasse aos seus acadêmicos maior possibilidade de participação em projetos de pesquisa [...], programas de estágio não obrigatório e monitorias; desejaria, ainda, que os acadêmicos fossem mais preparados para a área de atuação, não somente com teoria, mas também com atividades práticas.

Egresso do curso de Ciências Contábeis desabafou dizendo: "Saí da graduação sem saber como fazer a classificação fiscal/tributária de um produto ou serviço".

Para Dias Sobrinho (2008, p. 68):

A capacitação profissional, embora não seja a única e exclusiva função da educação superior, é uma das importantes e legítimas demandas da sociedade, cujo cumprimento, com qualidade, as instituições, os educadores e pesquisadores não podem recusar.

O processo de formação superior não se reduz à sala de aula; passa pela participação dos alunos em estágios profissionalizantes, em projetos de iniciação científica ou tecnológica, em eventos científicos, atividades complementares, entre outros.

Com base nesse pressuposto, perguntou-se aos egressos da IES quais atividades constituíram aprendizados diferenciados e significativos durante o processo de formação superior. Entre as atividades, destacaram-se: a realização de estágio obrigatório e não obrigatório (37,86\%); a elaboração do TCC (19,54\%); a participação em eventos $(16,24 \%)$; as atividades complementares $(9,80 \%)$; e a participação em projetos de pesquisa, extensão ou cultura $(8,48 \%)$. Por sua vez, a publicação de artigos científicos, o aprendizado de uma língua estrangeira ou o intercâmbio internacional pouco representaram enquanto diferenciais ao processo de formação superior, como mostra o Gráfico 4, até porque são poucos os alunos que se envolvem com essas atividades na graduação. 


\section{Gráfico 4 - Aprendizados diferenciados para a formação acadêmica}

A realização de estágio obrigatório e não.

A elaboração do Trabalho de Conclusão..

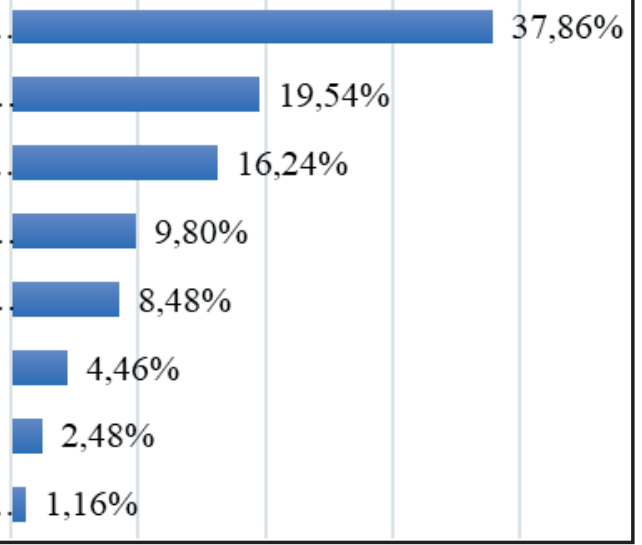

A participação em eventos promovidos..

As atividades complementares planejadas..

A participação em projeto de pesquisa,..

A publicação de artigos científicos

Aprendizagem de uma língua estrangeira

A participação em intercâmbio... $1,16 \%$

Fonte: Comissão Própria de Avaliação (UNOESC, 2018), p. 26.

O TCC constitui uma das mais importantes experiências de aprendizado pelas quais os estudantes passam, uma vez que possibilita o exercício da autonomia intelectual, do senso investigativo e da aplicação dos saberes assimilados ao longo do curso. Espera-se de um TCC que seus resultados possam contribuir com a solução de problemas do entorno da universidade.

Contudo, não foi essa a constatação apontada pelos egressos da IES. Apesar de ter sido reconhecido como diferencial formativo, em termos práticos, o TCC representou, para a maioria deles, um estudo meramente teórico-bibliográfico $(60,20 \%)$. Poucos foram os TCCs $(11,86)$ cujos resultados acabaram por gerar um produto ou um processo novo possível de aplicação. E o mais intrigante: apenas 1,16\% dos TCCs resultaram na criação da própria empresa/negócio, como mostra o Gráfico 5.

Gráfico 5 - Produtos/processos gerados a partir dos TCCs

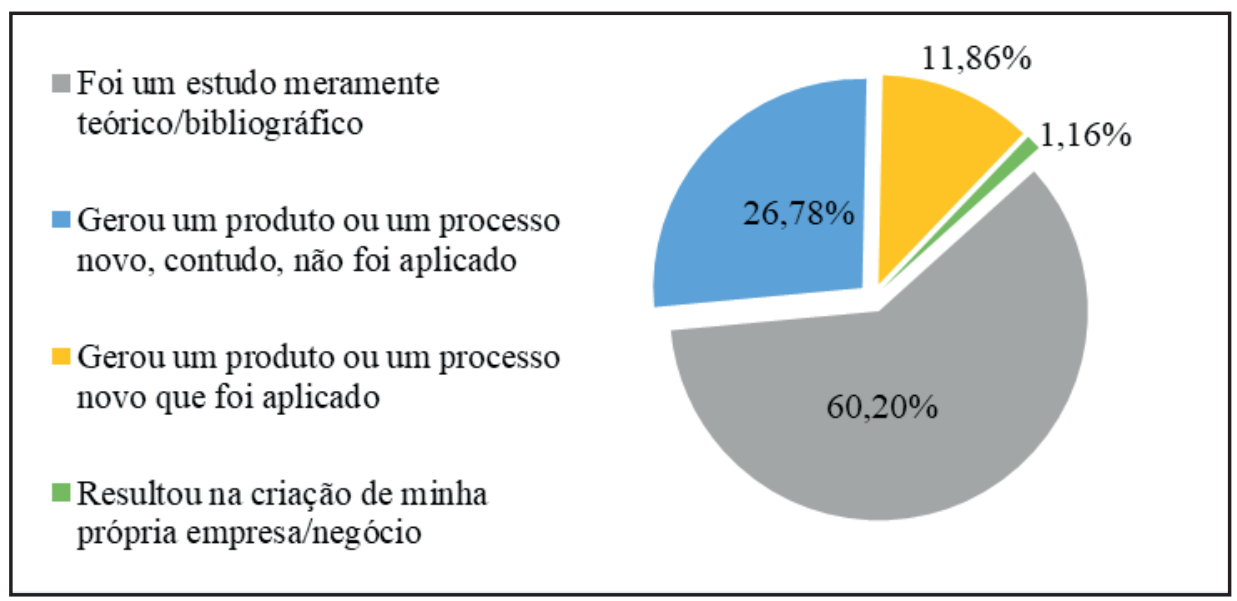

Fonte: Comissão Própria de Avaliação (UNOESC, 2018), p. 27. 
A mesma percepção em relação ao TCC foi expressa por um egresso do curso de Engenharia de Produção Mecânica: “[...] meu TCC fiz apenas para me formar, pois, por falta de incentivo da própria universidade, não consegui uma empresa para estagiar e meu TCC foi um trabalho inútil $[\ldots]$ "..".

A iniciação científico-tecnológica, inserida como política no contexto do ensino de graduação pelas universidades brasileiras, constitui outro diferencial no processo formativo dos estudantes, uma vez que desperta a vocação científica, revela novos talentos e prepara para a pós-graduação, agregando conhecimentos para além da sala de aula (PINHO, 2017).

Contudo, nem sempre os esforços empreendidos têm contribuído para a geração de novos processos/produtos, ou para a solução de problemas de alcance social, ou para a publicação de um artigo científico, como se esperaria. Na pesquisa feita junto dos egressos da IES em estudo, constatou-se que apenas um terço $(33,96 \%)$ dos projetos de iniciação científico-tecnológica desenvolvidos pelos estudantes resultaram em uma publicação científica, sendo que muitos deles $(34,91 \%)$ foram trabalhos de natureza meramente teórica, sem produzir resultados que pudessem ser aplicados ou gerado algum produto/processo novo; trabalhos dessa natureza foram poucos, apenas 13,68\%, como mostra o Gráfico 6 .

\section{Gráfico 6 - Resultados da iniciação científica/tecnológica empreendida na Unoesc}

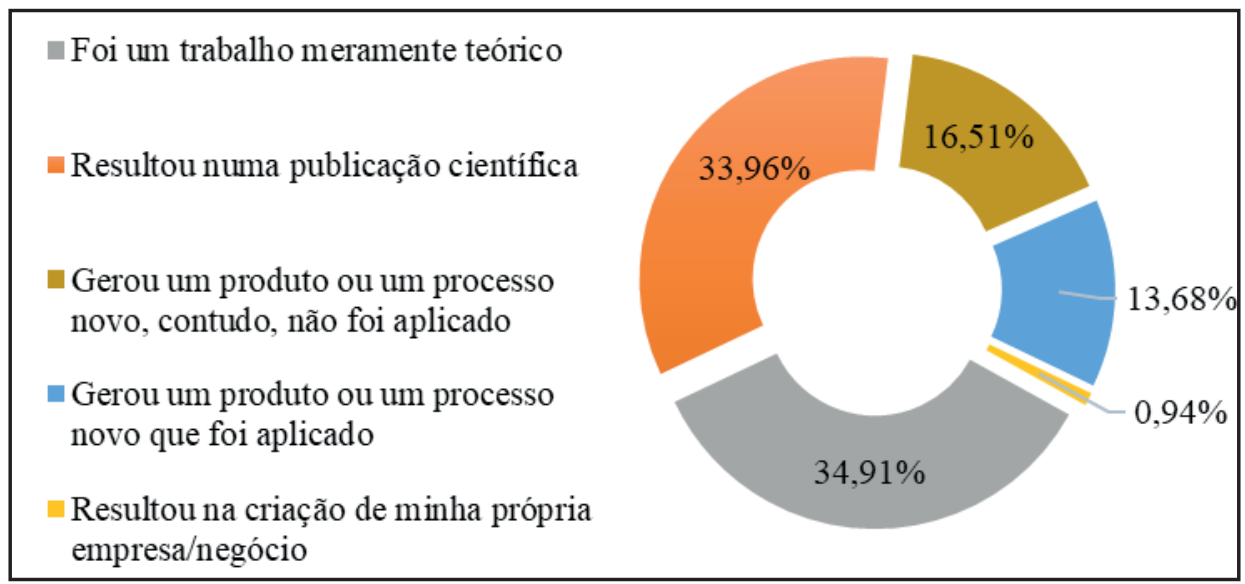

Fonte: Comissão Própria de Avaliação (UNOESC, 2018), p. 28.

O depoimento de um egresso do curso de Engenharia Sanitária Ambiental resume essa questão:

Acredito que seja fundamental aplicar mais aulas práticas aos cursos, aumentar os investimentos em pesquisas, bem como incentivar o empreendedorismo. De certa forma, vejo que a universidade não tem preocupação com os alunos na inserção destes no mercado de trabalho; poderia desenvolver um trabalho mais eficiente na parte de estágios, visto que são as primeiras oportunidades que estão faltando para se adquirir a tão almejada experiência. 


\section{CONSIDERAÇões FINAIS}

Os indicadores analisados neste estudo levam a algumas inferências. A primeira delas permite afirmar que a atuação de egressos no contexto socioeconômico de uma instituição comunitária de educação superior situada no interior do país, como é o caso da IES tomada como estudo, é diversa de outros modelos de universidade, por exemplo, o modelo público estatal de universidade, representado pelas universidades federais, ou o próprio modelo de universidade cujos fins são mercadológicos. Os alunos que se formam na IES em estudo são, em sua maioria, oriundos de classes sociais de baixa renda, conciliaram estudo e trabalho em seu processo de formação graduada, possuem dificuldades de ingressar no mercado de trabalho, de atuar na mesma área de formação e de ascender socialmente, como revelaram os dados já analisados.

No entanto, pode-se concluir por inferência que, apesar das dificuldades enfrentadas no mundo do trabalho, os egressos da IES, conforme estudo realizado pela sua CPA, possuem a percepção de que se formaram em uma instituição de qualidade $(33,90 \%)$, com credibilidade $(27,23 \%)$, inserida na comunidade regional $(16,40 \%)$ e preocupada com o desenvolvimento regional $(10,62 \%)$ e, por isso mesmo, encontram-se preparados para atuar profissionalmente, percepção expressa no depoimento de três egressos: i. "Atualmente sou gerente de uma grande rede de farmácias, graças aos conhecimentos adquiridos em minha formação" (Curso de Farmácia); ii. "Me formei no ano de 2010 na primeira graduação e em 2015 na segunda graduação. A instituição me abriu portas para o mercado de trabalho. Me preparou para enfrentar um concurso público com muito êxito" (Curso de Pedagogia); iii. "Somente tenho que agradecer aos professores e funcionários da instituição durante minha graduação. Sempre bem atendido por todos. Uma excelente instituição para crescer pessoalmente e profissionalmente" (Curso de Educação Física).

Os dados analisados fazem, igualmente, inferir que a IES necessita rever seus projetos pedagógicos de curso, inserindo metodologias e processos que levem à formação para o desenvolvimento de competências e habilidades criativas, para a solução de problemas e para o empreendedorismo. A formação para ser empregado de instituições públicas ou privadas não parece a missão da instituição universitária para o século XXI.

\section{REFERÊNCIAS}

ANDRIOLA, Wagner Bandeira. Estudo de egressos de cursos de graduação: subsídios para a autoavaliação e o planejamento institucionais. Educar em Revista, Curitiba, n. 54, p. 203-219, 2014. Disponível em: <http://www.scielo.br/pdf/er/n54/a13n54.pdf > Acesso em: 27 nov. 2018.

BARBOSA FILHO, Fernando de Holanda. A crise econômica de 2014/2017. Estudos Avançados, São Paulo, v. 31, n. 89, p. 51-60, 2017. Disponível em: <http://www.scielo.br/ pdf/ea/v31n89/0103-4014-ea-31-89-0051.pdf>. Acesso em: 28 nov. 2018. 
BARDAGI, Marucia Patta et al. Avaliação da formação e trajetória profissional na perspectiva de egressos de um curso de psicologia. Psicologia: ciência e profissão, Brasília, v. 28, n. 2, p. 304-315, 2008. Disponível em: <http://pepsic.bvsalud.org/pdf/pcp/v28n2/ v28n2a07.pdf>. Acesso em: 27 nov. 2018.

BORDIGON, Neusa; CIMADON, Aristides. O Sinaes: da concepção ao sepultamento. São Paulo: Conceito, 2012.

BOURDIEU, Pierre. La distinción. Criterio y bases sociales del gusto, 1979. Tradução de Maria Del Carmen Ruiz de Elvira, 1988.

BRASIL. Lei no . 10.861, de 14 de abril de 2004. Institui o Sistema Nacional de Avaliação da Educação Superior - SINAES e dá outras providências. Diário Oficial da União. Brasília, DF, 15 abr. 2004. Disponível em: <http://www.planalto.gov.br/ccivil_03/_ato20042006/2004/lei/110.861.htm>. Acesso em: 26 nov. 2018.

BRASIL. Lei no . 12.881, de 12 de novembro de 2013. Dispõe sobre a definição, qualificação, prerrogativas e finalidades das Instituições Comunitárias de Educação Superior - ICES, disciplina o Termo de Parceria e dá outras providências. Diário Oficial da União. Brasília, DF, 13 nov. 2013. Disponível em: <http://www.planalto.gov.br/ccivil_03/_Ato20112014/2013/Lei/L12881.htm>. Acesso em: 26 nov. 2018.

CARRIJO, Clarissa Irineu de Sousa et al. A empregabilidade de egressos de um curso de graduação em enfermagem. Rev. Enferm. UERJ, Rio de Janeiro, v. 15, n. 3, p. 356-363, 2007. Disponível em: <http://www.facenf.uerj.br/v15n3/v15n3a06.pdf>. Acesso em: 27 nov. 2018.

COLENCI, Raquel; BERTI, Heloísa Wey. Formação profissional e inserção no mercado de trabalho: percepções de egressos de graduação em enfermagem. Revista da Escola de Enfermagem da USP, São Paulo, v. 46, n. 1, p. 158-166, 2012. Disponível em: <http://www. scielo.br/scielo.php?pid=S0080-62342012000100022\&script=sci_abstract\&tlng=pt $>$. Acesso em: 27 nov. 2018.

COSTA, Maria Teresa Gomes da; CARVALHO, Luisa Cagica. A educação para o empreendedorismo como facilitador da inclusão social: um caso no ensino superior. Revista Lusófona de Educação, Porto, Portugal, n. 19, p. 103-118, 2011. Disponível em: <http:// www.scielo.mec.pt/pdf/rle/n19/n19a07.pdf>. Acesso em 29 nov. 2018.

COSTA LEMOS, Ana Heloisa da; DUBEUX, Veranise Jacubowski Correia; PINTO, Mario Couto Soares. Educação, empregabilidade e mobilidade social: convergências e divergências. Cadernos EBAPE. BR, Rio de Janeiro, v. 7, n. 2, p. 368-384, 2009. Disponível em: <http://www.scielo.br/pdf/cebape/v7n2/a12v7n2.pdf>. Acesso em: 11 dez. 2018.

EMMI, Danielle Tupinambá; SILVA, Daiane Maria Cavalcante da; BARROSO, Regina Fátima Feio. Experiência do ensino integrado ao serviço para formação em Saúde: per- 
cepção de alunos e egressos de Odontologia. Interface-Comunicação, Saúde, Educação, Botucatu, SP, v. 22, p. 223-236, 2017. Disponível em: <https://www.scielosp.org/pdf/ icse/2018.v22n64/223-236/pt>. Acesso em: 21 nov. 2018.

ESTADÃO. Diploma de engenharia volta para a gaveta. Revista Exame. Carreira Você S/A, 2 de julho de 2017. Disponível em: $<$ https://exame.abril.com.br/carreira/diploma-de-engenharia-volta-para-a-gaveta/>. Acesso em: 27 nov. 2018.

FOLHA DE SÃO PAULO. Ranking de universidades, 2018. Disponível em: $<$ http://ruf. folha.uol.com.br/2018/>. Acesso em: 17 jan. 2018.

FRANTZ, Walter; DA SILVA, Enio Waldir. As funções sociais da universidade: o papel da extensão e a questão das comunitárias. Ijuí, RS: Editora Unijuí, 2002.

INSTITUTO NACIONAL DE ESTUDOS E PESQUISAS EDUCACIONAIS ANÍSIO TEIXEIRA. Sistema Nacional de Avaliação da Educação Superior (Sinaes). Política Institucional de integração e de avaliação do egresso na melhoria da IES, v. 3. Brasília, DF: Inep, 2015. Disponível em: <http://portal.inep.gov.br/documents/186968/484109/SINAES>. Acesso em: 27 nov. 2018.

LIMA, Leonardo Araújo; ANDRIOLA, Wagner Bandeira. Acompanhamento de egressos: subsídios para a avaliação de Instituições de Ensino Superior (IES). Avaliação: Revista da Avaliação da Educação Superior, Campinas/Sorocaba, v. 23, n. 1, 2017. Disponível em: <http://www.scielo.br/pdf/aval/v23n1/1982-5765-aval-23-01-00104.pdf $>$. Acesso em: 19 nov. 2018.

LÜCKMANN, Luiz Carlos. Breve histórico da interiorização do ensino superior no Oeste catarinense. Fundação Universidade do Oeste de Santa Catarina. FUNOESC 50 anos: Fundação Universidade do Oeste de Santa Catarina/Rogério Augusto Bilibio (org.). Joaçaba: Editora Unoesc, 2018.

LÜCKMANN, Luiz Carlos; CIMADON, Aristides. A dimensão pública das instituições de educação superior comunitárias. Revista NUPEM, Campo Mourão, PR, v. 7, n. 12, p. 67-80, 2015. Disponível em: <http://fecilcam.br/revista/index.php/nupem/article/viewFile/660/459>. Acesso em: 19 nov. 2018.

MACHADO, Ana Maria Netto. Universidades comunitárias: um modelo brasileiro para interiorizar a educação superior. In: SCHMIDT, João Pedro. Instituições comunitárias: instituições públicas não-estatais. Santa Cruz do Sul: EDUNISC, 2009.

MEIRA, Maria Dyrce Dias; KURCGANT, Paulina. Avaliação de curso de graduação segundo egressos. Revista da Escola de Enfermagem da USP, São Paulo, v. 43, n. 2, p. 481-485, 2009. Disponível em: <http://www.scielo.br/scielo.php?pi$\mathrm{d}=\mathrm{S} 0080-62342009000200031 \&$ script=sci_abstract\&tlng=pt $>$. Acesso em: 27 nov. 2018. 
PALHARES, Isabela. Relatório da OCDE reprova exame brasileiro que avalia ensino superior. O Estado de São Paulo, 22 de dezembro de 2018. Disponível em: $<$ https://educaco. estadao.com.br/noticias/geral,relatorio-da-ocde-reprova-exame-brasileiro-que-avalia-ensino-superior,70002655128a >. Acesso em: 17 jan. 2018.

PINHO, Maria José de. Ciência e ensino: contribuições da iniciação científica na educação superior. Avaliação: Revista da Avaliação da Educação Superior, Campinas/Sorocaba, v. 22 , n. 3, p. 658-675, 2017. Disponível em: <http://www.scielo.br/pdf/aval/v22n3/ 1982-5765-aval-22-03-00658.pdf>. Acesso em: 17 dez. 2018.

SAMPAIO et al. Empregabilidade e perfil da inserção de egressos do IFRN no mercado de trabalho. VIII CONNEPI - Congresso Norte Nordeste de Pesquisa e Inovação. Salvador, Bahia, 2013. Disponível em: $<$ https://portal.ifrn.edu.br/pesquisa/egressos/artigo-apresentado-no-viii-connepi-pesquisa-piloto-de-acompanhamento-de-egressos-2012>. Acesso em: 22 jul. 2020.

SANTOS, Boaventura de Sousa. Um discurso sobre as ciências na transição para uma ciência pós-moderna. Estudos avançados, São Paulo, v. 2, n. 2, p. 46-71, 1988. Disponível em: <http://www.revistas.usp.br/eav/article/view/8489/10040>. Acesso em: 21 dez. 2018.

SANTOS, Carlos Eduardo dos; SANNA, Maria Cristina. Inserção dos egressos do curso de graduação em enfermagem de uma universidade particular do grande $\mathrm{ABC}$ no mercado de trabalho. Revista Brasileira de Enfermagem, Brasília, v. 56, n. 6, p. 630-633, 2003. Disponível em: <http://www.scielo.br/pdf/reben/v56n6/a07v56n6.pdf>. Acesso em: 27 nov. 2018.

SCHMIDT, João Pedro (Org.). Instituições comunitárias: instituições públicas não-estatais. Santa Cruz do Sul, RS: Edunisc, 2009.

SCHMIDT, João Pedro. Universidades comunitárias e terceiro setor [recurso eletrônico]: fundamentos comunitaristas da cooperação em políticas públicas/João Pedro Schmidt, 1. ed. Santa Cruz do Sul: EDUNISC, 2018.

SHIWA, Sílvia Regina; JOÃO, Silvia Maria Amado. O Perfil dos Fisioterapeutas Egressos da Faculdade de Medicina da Universidade de São Paulo. Revista de Graduação USP, São Paulo, v. 3, n. 2, p. 99-106, 2018. Disponível em: <http://www.revistas.usp.br/gradmais/article/view/147917>. Acesso em: 21 nov. 2018.

SILVEIRA, Zuleide, Simas da. BIANCHETTI, Lucídio. Universidade moderna: dos interesses do Estado-nação às conveniências do mercado. Revista brasileira de educação, Rio de Janeiro, v. 21, n. 64, 2016. Disponível em: <http://www.scielo.br/pdf/rbedu/v21n64/ 1413-2478-rbedu-21-64-0079.pdf $>$. Acesso em: 10 dez. 2018.

SIMON, Lilian Wrzesinski; PACHECO, Andressa Sasaki Vasques. Ações de acompanhamento de egressos: um estudo das universidades públicas do sul do Brasil. Revista Brasileira de Ensino Superior, Passo Fundo, v. 3, n. 2, p. 94-113, dez. 2017. Disponível em: <https:// seer.imed.edu.br/index.php/REBES/article/view/2023>. Acesso em: 27 nov. 2018. 
SOBRINHO, José Dias. Avaliação da educação superior: avanços e riscos. EccoS Revista Científica, São Paulo, v. 10, n. esp., p. 67-93, 2008. Disponível em: <https://www.redalyc. org/pdf/715/71509904.pdf>. Acesso em: 12 dez. 2018.

SOPELSA, Ortenila; RIOS, Mônica Piccione Gomes; LÜCKMANN, Luiz Carlos. O compromisso da universidade com a empregabilidade: concepção dos egressos e empregadores. Impulso, Sorocaba, SP, v. 22, n. 54, p. 73-84, 2012. Disponível em: <https://www. metodista.br/revistas/revistas-unimep/index.php/impulso/article/view/608/1013>. Acesso em: 21 nov. 2018.

TINTI, Élidi Cristina. Capitalismo, trabalho e formação profissional: dilemas do trabalho cotidiano dos assistentes sociais em Ribeirão Preto [on-line]. São Paulo: Editora UNESP; São Paulo: Cultura Acadêmica, 2015. Disponível em: <http://books.scielo.org/id/ qzyh6/pdf/tinti-9788579836558.pdf>. Acesso em: 21 nov. 2018.

UNESCO. Declaração Mundial sobre Educação Superior no Século XXI: Visão e Ação. Paris: UNESCO, 1998.

UNIVERSIDADE DO OESTE DE SANTA CATARINA. Análise dos resultados da avaliação da atuação dos diplomados da Unoesc no ambiente socioeconômico. Comissão Própria de Avaliação - CPA. Joaçaba: Editora Unoesc, 2018.

UNIVERSIDADE DO OESTE DE SANTA CATARINA. Plano de Desenvolvimento Institucional da Unoesc 2018-2022, 3. ed. Joaçaba: Editora Unoesc, 2018.

UNIVERSIDADE DO OESTE DE SANTA CATARINA. Relatório de autoavaliação institucional 2015-2017. Comissão Própria de Avaliação - CPA. Joaçaba: Editora Unoesc, 2018.

UOL EDUCAÇÃO. O impacto do ensino superior no salário dos recém-formados. AMPESC. Disponível em: <https://g1.globo.com/sc/santa-catarina/especial-publicitario/ampesc/admiravel-mundo-novo/noticia/2018/11/20/o-impacto-do-ensino-superior-no-salario-dos-recem-formados.ghtml>. Acesso em: 20 nov. 2018.

\section{DADOS DOS AUTORES:}

\section{Luiz Carlos LuckManN}

Professor da Universidade do Oeste de Santa Catarina. Santa Catarina/SC - Brasil. luiz. luckmann@gmail.com

\section{Aristides Cimadon}

Professor da Universidade do Oeste de Santa Catarina. Santa Catarina/SC - Brasil. aristides.cimadon@unoesc.edu.br

Submetido em: 23-3-2019

Aceito em: $29-7-2020$ 